\title{
Gilberto Freyre, professor e sistematizador da sociologia brasileira
}

Amurabi Oliveira'

\section{Resenha do livro:}

MEUCCI, Simone . Artesania da sociologia no Brasil: contribuições e interpretações de Gilberto Freyre. Appris: Curitiba, 2015.

Uma das sínteses mais conhecidas sobre os clássicos do pensamento social brasileiro (PSB) encontra-se no prefácio feito por Antônio Cândido (1918-2017) para quinta edição de Raízes do Brasil (2006 [1936]), publicada em 1969, que, de certo modo, cristalizou uma visão acerca de autores fundamentais para essa área de conhecimento. Em suas palavras:

Os homens que estão hoje um pouco para cá ou um pouco para lá dos cinquenta anos aprenderam a refletir e a se interessar pelo Brasil sobretudo em termos de passado e a partir de três livros: Casa-grande e senzala, de Gilberto Freyre, publicado quando estávamos no ginásio; Raízes do Brasil, de Sergio Buarque de Holanda, publicado quando estávamos no curso complementar; Formação do Brasil Contemporâneo, de Caio Prado Júnior, publicado quando estávamos na escola superior. São estes os livros que podemos considerar chaves, os que parecem exprimir a mentalidade ligada ao sopro de radicalismo intelectual e análise social que eclodiu depois da Revolução de 1930 e não foi, apesar de tudo, abafado pelo Estado Novo. (Cândido, 2006: 9).

1 Departamento de Sociologia e Ciência Política/ Programas de Pós-Graduação em Sociologia Política e em Educação da Universidade Federal de Santa Catarina (UFSC) - Florianópolis - Brasil - amurabi_cs@hotmail.com 
E mais adiante ele continua:

Para nós, os três autores citados foram trazendo elementos de uma visão do Brasil que parecia adequar-se ao nosso ponto de vista. Traziam a denúncia do preconceito de raça, a valorização do elemento de cor, a crítica dos fundamentos "patriarcais" e agrários, o discernimento das condições econômicas, a desmistificação da retórica liberal. Mas talvez significassem outra coisa para os jovens da direita, que em geral, se bem me lembro, tendiam a rejeitá-los, olhá-los com desconfiança ou, na medida do possível, ajustar ao menos o primeiro aos seus desígnios. (Cândido, 2006:11).

Esses autores e suas obras fundamentais são considerados um marco para as ciências sociais brasileiras, ainda que não sem algum dissenso. Neste sentido, é interessante destacar o fato de que a delimitação do que compreendemos como PSB é mais um exercício de atribuição que de inferência abarcando um conjunto de autores e trabalhos com preocupações muito distintas (Botelho, 2011). Mais que isso, recorrentemente tais autores são alçados a uma fase "pré-científica" das ciências sociais, sob a alçada do que chamamos de "ensaísmo" (Fernandes, 1977).

Partindo de uma compreensão em que se percebe “(...) a não existência de rupturas essenciais (ou de natureza?) entre os denominados ensaios de interpretação do Brasil e os estudos científicos sobre a sociedade, produtos da reflexão que se dará na universidade" (Botelho; Bastos, 2010: 478), o trabalho de Simone Meucci traz uma contribuição significativa para repensarmos a história das ciências sociais no Brasil, e de forma mais enfática o lugar de Gilberto Freyre (1900-1987) nesse processo.

O presente trabalho é oriundo de sua tese de doutorado intitulada Gilberto Freyre e a sociologia no Brasil: da sistematização à constituição do campo científico (2006), defendida no Programa de Pós-Graduação em Sociologia da Unicamp sob orientação da professora Élide Rugai Bastos. Em certa medida, este trabalho demarca uma continuidade em relação a sua dissertação de mestrado intitulada Institucionalização da sociologia no Brasil: primeiros manuais e cursos (2011 [2000]). Na pesquisa anterior, Meucci voltou-se para o processo de rotinização do conhecimento sociológico no Brasil com base nos primeiros manuais produzidos entre as décadas de 1920 e 1940, dentre os quais fora analisado o livro Sociologia: introdução ao estudo dos seus princípios (2009 [1945]), que destoava significativamente dos demais compêndios analisados no período. Como aponta a autora no prefácio que produziu para a nova edição deste trabalho de Freyre:

(...) o livro Sociologia de Freyre se distingue da primeira "safra" dos livros didáticos da matéria sociológica, redigidos por autores com pouca 
experiência na análise social. Sociologia faz parte de um novo conjunto de compêndios surgidos no Brasil nos anos 1940, do qual Teoria e Pesquisa em Sociologia (também publicado em 1945) de Donald Pierson é também um exemplar paradigmático.

De certa maneira, esses dois livros - de Freyre e Pierson -, mais do que mera reconstrução histórica e escolástica das etapas do pensamento sociológico, procuram realizar síntese original distinta das dezenas de livros didáticos de sociologia que até então ocupam as estantes das livrarias brasileiras. (Meucci, 2009: 15)

Pode-se afirmar que é a análise dessa obra tão singular é o fio condutor de Artesania da Sociologia no Brasil. Porém, Meucci realiza um esforço de pesquisa para adentrar no processo de elaboração deste compêndio, o que em muito antecede sua publicação, explorando uma faceta pouco conhecida de Freyre: a de professor. Ela estabelece um diálogo constante entre a concepção de sociologia presente no sociólogo-antropólogo - sempre com hífen como ele mesmo afirmara (Freyre, 1968) - e as transformações pelas quais o campo das ciências sociais foi passando, repensando seu lugar neste processo.

A primeira parte deste trabalho denomina-se "Experiência docente na escola normal de Pernambuco 1929-1930", na qual a autora explicita o contexto político e social no qual a atuação de Freyre estava inserida, bem como sua proximidade com o governador Estácio Coimbra (1872-1937). O então governador incumbiu Antônio Carneiro Leão (1887-1966) de promover reformas no sistema de ensino de Pernambuco, e dentre elas encontra-se a reforma da Escola Normal de Pernambuco. É interessante perceber aí o peso da Escola Nova nesta reforma, que implicou em modificações no currículo desta instituição, que passou a contar com a disciplina de Sociologia na formação de professores (principalmente professoras).

A proximidade pessoal de Freyre com o governador aparentemente tese peso em sua escolha como catedrático desta disciplina, mas também sua formação acadêmica obtida nos Estados Unidos, especialmente no campo das ciências sociais. ${ }^{2}$ Meucci acompanha desde o processo de "revelação" de Freyre como sociólogo a partir da atuação na Escola Normal, o que faz principalmente

2 Freyre realizou estudos de graduação na Universidade de Baylor no Texas, e de mestrado em História Social na Universidade de Colúmbia. De fato, ele chegou a cursar disciplinas em outros departamentos, incluindo de Antropologia e Sociologia, porém, sua afirmação como antropólogo e sociólogo ainda é bastante nebulosa, mas de fato possibilitou que ele ganhasse ainda mais visibilidade no campo intelectual de seu tempo (Motta, Fernandes, 2013). 
por meio do plano de ensino desta disciplina e das anotações de sua aula inaugural, até sua consagração como escritor em nível nacional com a publicação de Casa-Grande \& Senzala, em 1933. Meucci explora o fato de que, distando de outros de seu tempo que buscavam diferenciar a sociologia das demais ciências, Freyre aponta para a interdependência das ciências, e para o diálogo da sociologia com outras disciplinas, apresentando uma concepção bastante particular de ciência social a seu tempo.

A segunda parte denomina-se "Experiência docente na Universidade do Distrito Federal 1935-1937", que remete àquela que foi possivelmente o período mais longo de docência de Freyre, que, como é bem sabido, não era afeito à cátedra. Também realiza uma breve análise sobre o curso dado pelo autor na Faculdade de Direito de Recife, ainda que este tenha sido por um período mais curto. Sua inserção na Universidade do Distrito Federal (UDF) se deu por meio da intermediação de Anísio Teixeira (1900-1971), idealizador desta singular e breve experiência acadêmica brasileira. A autora também nos faz perceber as distinções entre a atuação de Freyre no caso anteriormente analisado e neste, uma vez que agora ele já era um autor de renome nacional, e sua presença na UDF agregaria prestígio a esta instituição, criadora de um dos primeiros cursos de ciências sociais no Brasil. ${ }^{3} \mathrm{O}$ interstício de sua atuação da UDF coincide com o período em que ele estava trabalhando na produção de Sobrados e Mucambos, publicado em 1936, que viria a compor sua Introdução à História da Sociedade Patriarcal no Brasil.4 Além da atuação como docente, Meucci também destaca a criação do Club de Sociologia, que contava com a participação de outros intelectuais da época, como Heloisa Alberto Torres (1895-1977).

Meucci parte principalmente das aulas taquigrafadas de Freyre referentes às disciplinas por ele assumidas no período: "Antropologia", "Sociologia Geral" e "Pesquisas e Inquéritos Sociais". Este rico material revela nuances do pensamento do autor, assim como uma certa concepção de ciências sociais. Mais que isso, é por meio das aulas que Meucci indica a forma como Freyre compreendia que deveria ser tratado o ensino dessas ciências, longe de abstrações teóricas e mais próximo da prática (o que já havia sido apontado em sua atuação na Escola Normal de Pernambuco), o que também pode ser interpretado a partir

3 Os cursos de ciências sociais foram criados no Brasil na década de 1930, sendo os primeiros o da Escola Livre de Sociologia e Política de São Paulo (1933), da Universidade de São Paulo (1934) e da Universidade do Distrito Federal (1935).

4 Esta introdução é composta por três livros, os já citados Casa-Grande \& Senzala e Sobrados e Mucambos, e mais Ordem e Progresso, publicado em 1957. Haveria um quarto livro, que se intitularia Jazigos e Covas-Rasas, porém, ele não chegou a ser escrito. 
da influência americana em sua formação (Oliveira, 2014). Além do mais, também é apontada para a posição ambivalente que Freyre assume ante o Estado Novo, com destaque para sua aproximação com Gustavo Capanema (1900-1985) e para a utilização de suas ideias por este regime.

A terceira e última parte denomina-se "O livro Sociologia em debate sociológico", na qual Meucci volta-se mais cuidadosamente para o livro Sociologia, de Freyre, compreendo que por meio dele ele expressa sua visão acerca da sociologia e da sociedade. Como ela bem enfatiza, o cenário no qual esse livro foi publicado, já em 1945, é bem diferente daquele no qual foi produzida a primeira safra de manuais de sociologia, nos anos de 1920, uma vez que a sociologia já não integrava mais o curso secundário, ${ }^{5}$ e havia em curso um claro processo de profissionalização das ciências sociais. Meucci indica que o compêndio de Freyre pertencia a uma nova geração de manuais, juntamente com o livro Teoria e Pesquisa em Sociologia, de Donald Pierson (1900-1995), publicado no mesmo ano. Para a autora, nesta obra Freyre se opunha ao marxismo, ao evolucionismo, à sociologia cristã e às perspectivas mais progressistas.

Apesar de Freyre recorrentemente preferir deixar seus conceitos um tanto nebulosos (Motta, 2009), em Sociologia, devido a seu caráter didático, há uma maior clareza na delimitação destes. Tanto a relação da sociologia com as demais ciências ganharia visibilidade neste trabalho quanto o esclarecimento em torno de sua concepção de raça, conceito que como bem pontua Araújo (1994) é bastante impreciso em Casa-Grande \& Senzala. A raça, sempre grafada com aspas em Sociologia, seria uma categoria que, nos termos que Freyre elaborou, fugiria de determinismos, porém, em um intenso diálogo também com os fatores biológicos, ecológicos, culturais e históricos.

Meucci situa os esforços de Freyre na atualização do debate sociológico de sua obra, como pode ser percebido pelas contínuas reedições (1957, 1962, 1967, 1973), ${ }^{6}$ em meio às transformações das ciências sociais brasileiras, principalmente no contexto da profissionalização ocorrida na década de 1950, o que implicou também numa série de críticas a seu trabalho. A autora demonstra como Freyre buscou afirmar a proximidade da perspectiva sociológica de Georges

5 Apesar de haver experiências pontuais da sociologia no currículo escolar ainda no século XIX, é principalmente a partir das Reformas Rocha Vaz (1925) e Francisco Campos (1931) que ela passa a se consolidou no currículo escolar, tendo sido retirada através da Reforma Capanema (1942), que extinguiu os cursos complementares, nos quais a sociologia estava alocada (OLIVEIRA, 2013).

6 Freyre revisitava continuamente seus trabalhos, modificando-os, inserindo novos prefácios, capítulos e notas, o que recorrentemente se dava em resposta às críticas recebidas, ainda que raramente nomeasse seus críticos. Também estes novos "acréscimos" eram recorrentemente utilizados para que ele apontasse para a recepção de seus trabalhos, especialmente no exterior. 
Gurvitch (1894-1965) e a sua, esta aproximação com o meio intelectual francês também seria reforçada pela recepção positiva de Casa-Grande \& Senzala naquele país. Aponta ainda para a dimensão que a questão regional assume na obra de Freyre, sendo profundamente relevante para a compreensão de sua sociologia a questão da diversidade cultural e regional. Para a autora, as disputas travadas no campo da sociologia, das quais a relação de Freyre com seus críticos é paradigmática, também refletiriam às disputas em torno da definição dos valores norteadores no encaminhamento do processo histórico do país.

Certamente, Artesania da Sociologia no Brasil traz contribuições significativas para o campo do PSB, lançando novos olhares sobre a produção sociológica de Freyre, bem como sobre o lugar que ele ocupou no processo de sistematização da sociologia brasileira. Como bem nos indica a autora, o embate entre a sociologia de Freyre e a chamada sociologia científica é um dos momentos mais interessantes da sociologia brasileira no Século XX, que se desdobra também numa maneira peculiar de compreendermos os projetos de modernidade e de sociedade que estavam em jogo. Como nos coloca Roberto Motta em entrevista acerca da área do PSB:

A meu ver a questão fundamental ainda é a dos modelos de sociedade e de história. Isto é, haverá um modelo normativo? Já que duas vezes mencionei Gilberto Freyre, eu diria que uma questão premente está na avaliação, aceitação ou recusa da interpretação freyriana do Brasil, isto ainda mais depois da aparente obsolescência do modelo marxista. (Schwarcz; Botelho, 2011: 158).

Creio que para compreendermos essa questão o trabalho de Meucci é um dos mais enfáticos e originais produzidos em período recente, visibilizando ainda a relevância das reformas educacionais para a institucionalização da sociologia no Brasil. Por fim, não sem menor relevância, cabe ressaltar que o trabalho da autora também é sintomático das próprias mudanças que vêm ocorrendo no campo do PSB, das possibilidades abertas pelo reexame desta área e de autores significativos no processo de constituição das ciências sociais brasileiras, mas que durante muito tempo foram relegados à alcunha de anticientíficos e provincianos, porém, Meucci consegue com perspicácia demonstrar que não é possível captar o pensamento de Freyre apenas recorrendo a estas simplificações.

\section{Referências}

ARAÚJO, Ricardo Benzaquen. Guerra e Paz: Casa-Grande er Senzala e a obra de Gilberto Freyre nos anos 30. Rio de Janeiro, Editora 34, 1994, 216 p. 
BOTELHO, André. Passado e futuro das interpretações do país. Tempo Social, v. 22, n. 1, 2010, pp. 47-66.

BOTELHO, André; BASTOS, Élide Rugai. Pensamento Social Brasileiro. In: MARTINS, Carlos Benedito; MARTINS, Heloisa Helena. (Org.). Horizontes das Ciências Sociais: sociologia. São Paulo, ANPOCS, 2010, pp. 475-496.

CÂNDIDO, Antônio. O significado de Raízes do Brasil. In: HOLANDA, Sergio Buarque. Raízes do Brasil. São Paulo, Companhia das Letras, 2006, pp. 9-21.

FERNANDES, Florestan. A Sociologia no Brasil: contribuições para o estudo de sua formação e desenvolvimento. Petrópolis, Vozes, 1977, 256 p.

FREYRE, Gilberto. Como e porque sou e não sou sociólogo. Brasília, Editora da Unb, $1968,189 \mathrm{p}$.

MEUCCI, Simone. Institucionalização da sociologia no Brasil: primeiros manuais e cursos. São Paulo, Hucitec; FAPESP, 2011, 169 p.

. Artesania da Sociologia no Brasil: contribuições e interpretações de Gilberto Freyre. Curitiba, Appris, 2015, 363 p.

. Prefácio à presente edição: singularidades, revelações e ocultações da "Sociologia de Gilberto Freyre”. In: FREYRE, Gilberto. Sociologia: introdução ao estudo dos seus princípios. São Paulo, É Realizações, 2009, pp. 11-26.

MOTTA, Roberto; BASTOS, Élide Rugai. Gilberto, Imagismo e Língua de Universidade. Revista Brasileira de Ciências Sociais, v. 24, n. 69, 2009, pp. 185-206.

MOTTA, Roberto; FERNANDES, Marcionilia. Gilberto Freyre, um enigma genealógico. In: (Ogs.) Gilberto Freyre: região, tradição, trópico e outras aproximações. Rio de Janeiro, Instituto Miguel de Cervantes, 2013, pp. 11-36.

OLIVEIRA, Amurabi. Educação e Pensamento Social Brasileiro: alguns apontamentos a partir de Florestan Fernandes e Gilberto Freyre. Revista de Ciências Sociais, v. 45, n. 1, julho 2014, pp. 15-44.

OLIVEIRA, Amurabi. Revisitando a história do ensino de Sociologia na Educação Básica. Acta Scientiarum. Education, v. 35, n. 2, jul-dez 2013, pp. 179-189.

Recebido em 28/09/2017

Aprovado em 07/11/2018

\section{Como citar esta resenha:}

OLIVEIRA, Amurabi. Gilberto Freyre, professor e sistematizador da sociologia brasileira. Contemporânea - Revista de Sociologia da UFSCar, v. 8, n. 2, jul.- dez. 2018, pp. 679-685. 